\title{
Uncovering Relationships between Being Influential, Participating in Multiple Forums, and having Many Social Ties in Water Governance in Brazil
}

\author{
María Mancilla García ${ }^{1}$ \\ Stockholm Resilience Centre, Stockholm University, Sweden \\ Örjan Bodin \\ Stockholm Resilience Centre, Stockholm University, Sweden
}

\section{Abstract}

Social network analysis has long been used to explore the networks actors build around collaborative institutional arrangements, and to uncover factors explaining why certain actors are more central than others. Being central in a social network is often treated as interchangeable with being influential. We critically investigate this common assumption by drawing inspiration from structuration theory. We use the management forum of the river Paraíba do Sul in Brazil as our empirical case study, and deploy social network analysis and structural equation modeling to disentangle influence ratings and social network centrality. We analyze direct and indirect factors that potentially explain centrality in information exchange and high influence ratings, and how they relate to each other. Our results show that centrality and influence are highly correlated, but also that they are not the same. We draw on interviews to suggest why some actors are influential without being central and vice versa.

Keywords: qualitative data, social structuration theory, structural equation modeling, water basin governance

\section{Introduction}

Social network analysis has long been used to explore the networks actors build around collaborative institutional schemes and to uncover the factors that explain why certain actors are more central than others (i.e., have more social ties than others). In the literature using social network analysis, being central in a social network is often treated as interchangeable with being influential. In this paper, we

1 Corresponding author: maria.mgarcia@su.se. 
take a perspective inspired by social structuration theory in trying to disentangle if there is a difference - and what could explain it—between centrality and influence in a particular case of water governance in Brazil, the water basin committee with jurisdiction over the river Paraíba do Sul. Social structuration theory argues that both structure and agency are crucial to understanding social dynamics—or, said otherwise, that structure is dual: It sets both the conditions for agency and the outcome of agents' behavior. Social structuration theory also provides an interesting conceptualization of actors as knowledgeable and powerful, at least to a certain extent. While acknowledging that actors do not know everything and that their acting might produce unintentional outcomes, social structuration theory argues that actors know, at least to some extent, what they do and why they do it, which is what allows them to change existing structures instead of being predestined to certain structural positions with associated behaviors. Structuration theory is a useful perspective for studies on power and influence in that it provides a middle ground between the literature that asserts that power is largely formed and shaped by actors who intentionally or unintentionally create alliances with others (i.e., create and dissolve social ties with others), and the literature that dismisses the effects of such networks to argue that power resides in deeper preexisting structures or attributes (culture, class, wealth, etc.). In this paper we try to disentangle influence ratings and social network centrality (which derives from actors' networking activities) to investigate links between influence and information exchange on a peer-to-peer basis (the social ties).

For this purpose, we combine social network analysis with two other methods: qualitative analysis of open-ended interview data, and structural equation modeling. Our mixed methods approach helps us explore direct and indirect factors that could explain centrality in information exchange and high influence, as well as if and how they relate to each other. Semi-structured interviews, in particular, help us put forward explanations as to why some actors are influential without being central and vice versa. We investigate these issues for the case of the river Paraíba do Sul management system in Brazil, and we particularly focus on the network of information exchange among actors involved in CEIVAP ("Comitê para Integração da Bacia Hidrográfica do Rio Paraíba do Sul," or "Integration Committee of the Paraíba do Sul River"), the basin-based forum for the management of the river.

\section{Theoretical framework}

An extensive body of research on power and influence in governance has investigated to what degree agency plays a more prominent role than structure (or vice versa) in explaining power dynamics. Following Lister, agency can be defined as characteristic of "autonomous, purposive and creative actors, capable of a degree of choice" (Lister, 2004, p. 125). The literature on leadership, for example, tends to put 
a stronger emphasis on agency than on structures, exploring possibilities for social change dependent on the behavior of key actors (e.g., Ardoin et al., 2014). Much of the literature in political ecology, by contrast, calls attention to the structuresaccess to resources or discursive framings (e.g., Bakker, 2013; Budds \& Hinojosa, 2012) that condition and limit the possibilities for individual choice.

The literature has extensively investigated what explains who are the most influential actors in a given governance arena. Some of the literature considers that the most influential actors will come from a specific group — the group of the powerful—which translates into the exclusion of historically less powerful actors (Dür \& de Bièvre, 2007; Few et al., 2007). We find this underlying hypothesis in different literature streams, such as in the institutionalist tradition that holds formal authority as the main way to become influential (Dahl, 1994), or the literature on interest groups that calls attention to the importance of financial resources to become influential (Yackee \& Yackee, 2006). From this perspective, whether an actor is central or not is simply a by-product of them being influential (i.e., if the powerful actors are central in the network, they are central because they are powerful). Therefore, the relations that actors cultivate do not play a significant role in determining their influence, since there isn't much any given actor can do in this regard to become influential. This can be read as a form of structuralism, since existing structuresin terms of current distributions of resources-determine influence and current power distributions. This indeed resonates with the structuralist idea that actors are embedded in social structures that they cannot change by themselves, or, in a milder version, that are extremely difficult to change and where changes would typically be systemic - that is, the structures themselves might change over time, and these changes might then lead to a redistribution of influence.

Other perspectives defend the position that power is to a significant extent constituted through the relations established in networks (i.e., being "well-connected" makes you influential). Some studies have, for example, discussed whether actors become more central because they already occupy quite a central position in the studied network- that is, because other actors want to link up with those who are central. In the social network analysis literature, being central in a social network is often treated as interchangeable with being influential (e.g., Burt, 2003), because centrality is associated with influence (Berardo, 2013; Gebara et al., 2014). However, in this paper we seek to investigate if centrality in the information exchange network and high influence can be teased apart, as well as the causal mechanisms that possibly link influence and centrality in the information exchange network. With this in mind, we investigate the extent to which being influential, on the one hand, and being central, on the other hand, can be explained by attributes and/or by actors' networking activities. We find inspiration in Giddens's (1984) structuration theory, which asserts that individuals through their actions confirm or weaken social structures. Individuals always act within social structures, but they can change them either unintentionally while they act or by being actively reflective upon them. For example, 
they might disapprove of current structures - in terms of fairness or distribution of benefits - and explicitly seek to change them (Ostrom, 2005). On the other hand, individual actions can also reproduce social structures unintentionally (by repeating habits, for example) or intentionally (such as by maintaining traditions). To sum up, both structure and agency play a role in structuration theory through recurrent and continuous action (Giddens, 1984). As Morse et al. (2013, p. 59), following Stones (2005), put it; "by focusing on the interaction of structures and agents, structuration theory avoids the oversimplification of purely objective or subjectivist approaches." This interplay between agency and structure-as co-constitutive-is what Giddens calls "the duality of structure" which is both an outcome of and a condition for action.

Giddens, and others after him such as Lister (2004), put forward a definition of agency that goes beyond intentional choice. Instead they link agency (or "political agency" in Lister's case) to the outcome of actions, and particularly to the possibility of changing a given state of affairs; that is, the possibility of affecting structures. As Long and Long (1992, p. 23) describe:

agency (and power) depend crucially upon the emergence of a network of actors who become partially, though hardly ever completely, enrolled in the projects and practices of some other person or persons. Effective agency then requires the strategic generation/manipulation of a network of social relations.

This provides a much more nuanced perspective on structures, in which structures not only condition actions but are actively engaged in action. As Morse et al. (2013, p. 60) explain: "An agent's capabilities, in part, come from their ability to utilize elements of structure (rules and resources) to achieve their goals". Networks provide a concrete, useful tool to conceptualize the constant coevolution between agency and structure. Networks are the product of repeated interactions, and while they happen within social structures, they are also structures in themselves that can change as actors act.

Building on the underlying assumption that influence and information exchange are sufficiently different (i.e., not just two measures of exactly the same thing), we develop a set of hypotheses that allow us to explore the relations between the two. We start by investigating whether influence and information exchange are strongly associated in the context of water governance in our study area. If these factors are sufficiently separated (i.e., not too strongly correlated), it means there is leverage for investigating causal mechanisms explaining how these factors potentially relate to each other. We firstly investigate if and how being centrally positioned in the information exchange network relates to being influential and formulate the following hypothesis:

Hypothesis 1 ( $\mathrm{H} 1)$ : Centrality in the information exchange network is strongly associated with influence. 
Recent work by Fischer and Sciarini (2016) tests whether actors tend to link up to exchange information with those who are perceived as more influential, considering that perceived influence would render actors attractive to others. Inspired by this work, we formulate two contrasting hypotheses about the causal direction:

Hypothesis $2 \mathrm{~A}(\mathrm{H} 2 \mathrm{~A})$ : The more influential an actor is, the more central they are in the information exchange network.

Hypothesis 2B (H2B): The more central an actor is in the information exchange network, the more influential they are.

Additionally, recent work on the ecology of games suggests that issues of influence and centrality in environmental governance networks need to be re-explored in the face of institutional systems where actors can choose to participate in a multitude of forums (Lubell et al., 2010). Specifically, some of these works have investigated which variables explain high influence in this particular empirical case: In Mancilla García and Bodin (2018), it was found that the number of forums attended was significant in explaining high influence. If high influence and information degree centrality derive from a common cause-in this case, actors building influence (at least partly) by exerting their agency through networking activities (captured by multiple forum participation) — then we might expect that the number of forums attended will also be significant in explaining information degree centrality. In order to account for the effect of forum participation on the two variables of interest, we formulated another hypothesis.

Hypothesis $3(\mathrm{H} 3)$ : The number of forums attended has a direct effect on both influence and information exchange centrality.

If this hypothesis was confirmed, then it would mean that influence and degree centrality are-at least to a certain extent-caused by networking activities rather than by structural phenomena, assuming that forum participation is the result of deliberate action and not of inherited attributes of power. Finally, to try and further disentangle the links between information degree centrality and influence, we formulated our last two hypotheses:

Hypothesis 4A (H4A): The effect of forum participation on information exchange centrality is to a large extent meditated through its effect on influence.

Hypothesis 4B (H4B): The effect of forum participation on influence is to a large extent meditated through its effect on information exchange centrality.

These hypotheses build on the assumption that forum participation affects both factors of centrality in the information exchange network and influence, but that each of these effects largely occurs through mediation by the other factor. In essence, the hypotheses on the indirect effects of forum participation on influence and information exchange, respectively, accommodate the hypotheses on the effect 
of perceived influence on information exchange centrality $(\mathrm{H} 2 \mathrm{~A})$ and vice versa (i.e., that information exchange has an effect on perceived influence [H2B]). These hypotheses specify a direct relationship between information exchange centrality and influence, albeit with different directionality. The last two hypotheses (H4A/B) on the mediated effects of forum participation allow us to investigate whether participating in multiple forums provides an opportunity to build network ties and whether these ties are what make actors influential. Overall, these hypotheses build on the assumption that there are several ways to gain influence, and, therefore, multiple causal relationships that can help explain why certain actors are more influential than others. Assuming that these causal links are directional, we triangulate the use of structural equation modeling (hereafter SEM) with our qualitative insights to support our claims on causal directionality. SEM is a modeling approach, building from path analysis, that allows the analyst to explicate and test a series of causal assumptions between a set of variables in one coherent model (Kaplan, 2009).

Finally, we acknowledge that there might be other factors that explain information centrality. In particular, the more time and energy an actor dedicates to their participation in the forum under study, the more opportunities to interact with other participants and establish relationships with them (Hileman \& Bodin, 2018). Hence, we used "degree of involvement" as a control variable when investigating centrality in the information exchange network.

\section{Case study}

We chose the case of the governance system of the river Paraíba do Sul to test these hypotheses for three reasons: (1) a multiplicity of actors from diverse backgrounds participates in the forum set up to manage the river, which provides ample opportunities to investigate the question of whether centrality in the information exchange network and influence are solely related to actors' attributes or to their networking activities; (2) this forum has existed for more than 20 years, and some actors have participated in it since its foundation, which implies that any transient effects deriving from the establishment of the forum have disappeared; and (3) besides the forum on which we focus here, multiple participatory forums for water management coexist at both the same and different levels (basin, subbasin, state levels), which constitutes an interesting setting to explore the effect of multiple forum participation on influence and centrality in the information exchange network.

The Paraíba do Sul river flows through the states of Rio de Janeiro, Minas Gerais, and São Paulo (see Figure 1) and covers a basin area of $56,500 \mathrm{~km}^{2}$, providing water for 17.5 million people. The main water uses are provision for human consumption (drinking, cooking, washing, etc.), sewerage (dilution of used waters), irrigation, and hydroelectricity generation. 


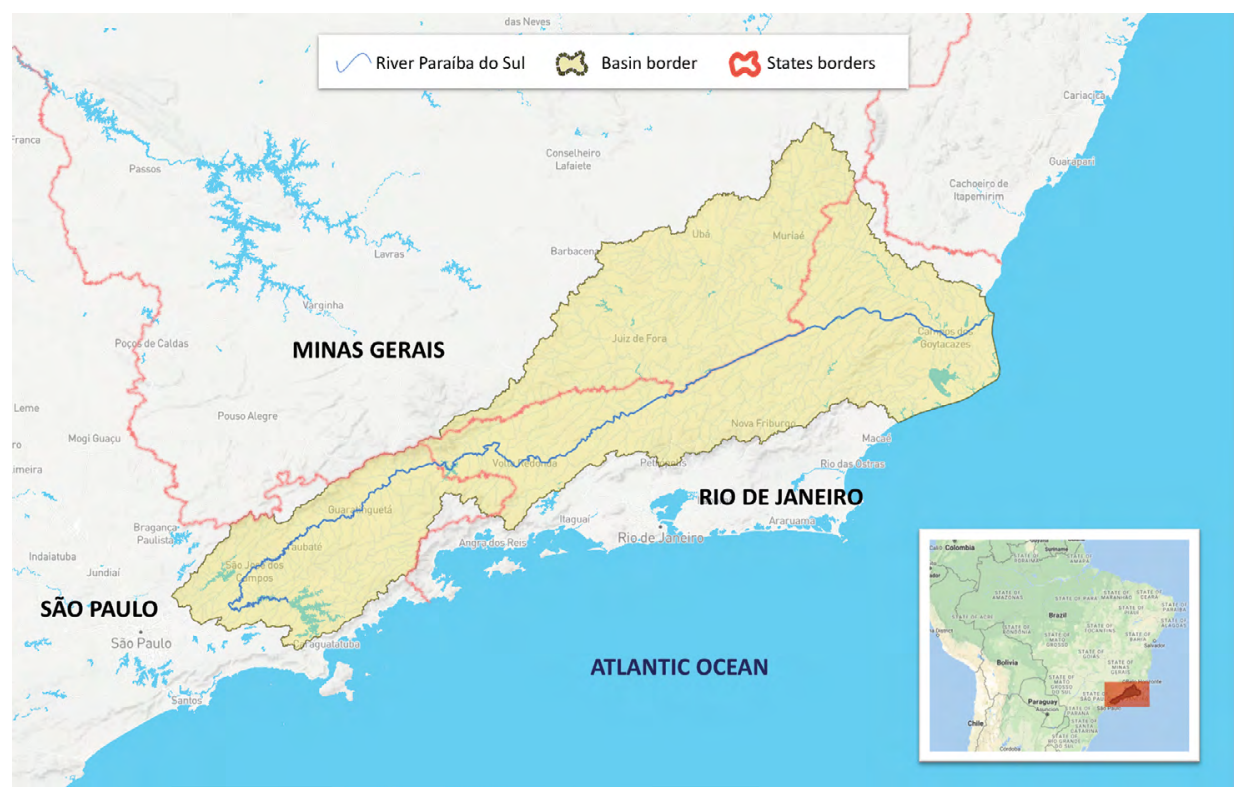

Figure 1. Water basin of river Paraíba do Sul.

Source: Mancilla García \& Bodin (2018).

The federal basin committee of the Paraíba do Sul river, CEIVAP, ${ }^{2}$ has overarching responsibility for the management of the system. The committee's main responsibilities encompass: determinations for the rights of use and the values of payment for water use; the definition of the quality of the river's water; and approval and implementation of the Water Resources Plan for the basin. CEIVAP was created in 1996. Its statutes define that 40 percent of plenary members represent the private users (industries, hydroelectric companies, agriculture, provision companies, etc.); 35 percent represent governmental entities at the federal, state, and municipal levels; and 25 percent represent civil organizations (associations, nongovernmental organizations [NGOs], universities). The representatives of these three categories are equally distributed between the three states. Besides the plenary, CEIVAP includes a technical chamber-composed of six members per state, two from each category (private users, government entities, civil society) - and several working groups. Additionally, the plenary elects a three-member directorate for two years with one representative from each category (private, government, civil), and each of those from a different state. Representatives of government entities hold the presidency, which rotates between the three states.

2 Comitê para Integração da Bacia Hidrográfica do Rio Paraíba do Sul (Integration Committee of the Paraíba do Sul River). 
The water resources management legislation currently in force in Brazil was approved in 1997, through law 9433. This law is founded on the principles of Integrated Water Resources Management and creates water resources councils at the state and national levels. ${ }^{3}$ Brazilian basin committees are embedded within a web of participatory organizations for water management (see also Mancilla García \& Bodin, 2018, 2019).

\section{Methods}

The sample included in our quantitative analysis consists of the participants in the water basin committee CEIVAP's plenary, provided that they fulfilled one condition: having attended at least two of the last six plenary meetings. This resulted in a sample of 45 people, three of whom declined to participate in the study - a response rate of 93 percent.

We presented respondents with the list of participants in CEIVAP's plenary and asked them to evaluate each participant following two criteria: whether they shared information with them and whether they saw them as influential over the management system of the river Paraíba do Sul. The first question was rated on a four-point scale, where 1 means "rarely or never," 2 means "sometimes," 3 means "often," and 4 means "constantly." Based on responses to this first question, we created the network of information exchange. While we acknowledge there are many types of centrality measures, we focused on in-degree centrality, which is the simplest measure and typically correlates strongly with other measures of centrality such as betweenness centrality.

The other question evaluated perceived influence on a five-point scale, where 1 was "not at all" and 5 "completely." For both scales, 0 indicated a participant unknown to the interviewee. We used influence perception as a measure of reputational power following Fischer and Sciarini (2016); perceived influence was assessed based on the average rating from all other actors responding with a 1 or above. We used a normalized measurement in which all 0 responses were disregarded, since 0 indicated that the actor was unknown to the interviewee, who, therefore, could not assess their level of influence.

Additionally, we asked actors a series of descriptive questions about their own participation in the water management system that allowed us to develop a set of attributes and variables to further explore actors' behavior and strategies.

\footnotetext{
3 Integrated water resources management is one of the most broadly implemented approaches to water management and is supported by multilateral agencies and governments across the globe. It was developed by engineers in the 1940s but was broadly institutionalised in the 1990s (Mancilla García, 2015). It proposes to align management with the watershed through the creation of water basin councils at that state and national scales. It proposes a participatory approach, although it has been extensively criticised for doing so uncritically (Mancilla García, Hileman \& Bodin, 2019).
} 
We asked participants to list other forums in which they participated to discuss water management issues. We also asked participants the degree to which they were involved in CEIVAP (on a 1-to- 4 scale where 1 is "not at all" and 4 is "a fundamental aspect of my work"), which we used in the analysis as a control variable.

To complete these data, we ran extensive semi-structured interviews with participants in the CEIVAP plenary during which they could speak about their general views on the system of management. Finally, we attended and took notes on plenary committee meetings, those of the technical chamber, and some meetings of other forums involving CEIVAP participants. The qualitative data were analyzed following a thematic analysis in which different themes were identified based on actors' responses to the questions as well as on other themes that emerged from reading and summarizing the data. This allowed us to create codes around the discussion of power issues, strategies to improve the system, actors' specific agendas, and broader issues relating to difficulties with ensuring meaningful participation. These thematic codes served to retrieve useful data for the analysis provided here.

The quantitative data were analyzed through descriptive statistics, network regression, and structural equation modeling (SEM). We acknowledge that standard regression techniques are often problematic when analyzing network data due to potential data interdependencies. In this case, the potentially most problematic network-based variable would be the social ties in the information exchange network. Perceived influence is constructed in a similar way (a network-centric data structure), but is, as we argue, a less problematic variable since it does not represent "working" relationships among actors (that could imply autocorrelation-i.e., if you work together you could develop similar traits, and/or you might choose to work with others because they have similar traits). Rather, it represents individuals' independent perceptions of other actors' level of influence. Nonetheless, when testing whether centrality in the information exchange network is strongly associated with influence (H1) we used a quadratic assignment procedure (QAP), a network regression model (Krackhardt, 1988) implemented in the software UCINET (Borgatti et al., 2002) where significance levels are estimated based on a large number of permutations. This allowed us to overcome the possible problems posed by data interdependency (autocorrelation), a feature that standard statistical analysis struggles with.

Although we acknowledge the potential difficulties with the network data primarily related to information exchange, the potential effect of autocorrelation on the residuals would be reduced when modeling each node's total degree centrality, since that measure represents an aggregate measure drawn from the entire network. Assuming that a direct tie between two actors also implies that the data associated with these actors are interdependent to some extent, the level of interdependency would then decrease since the node-level variable degree centrality, for each and every node (actor), is typically composed of many different direct relationships. 
For all other hypotheses (H2-H4) we used SEM. We used the Akaike information criterion (AIC), the root mean square error of approximation (RMSEA), and comparative fit index (CFI) to compare the level of fit for different SEMs. In order to compute all these measures of model fit, we had to use normal standard error estimates. Nonetheless, we also ran these models using robust standard errors, and no noteworthy differences between estimated effect sizes and significance levels were observed.

Throughout the quantitative analysis we used our qualitative data to further investigate our hypotheses and particularly tried to disentangle the reasons behind observed patterns of relationships among different variables. This allowed us to get a better understanding of the particularities of the case and to propose avenues for future research.

\section{Results of the quantitative analysis}

We started our analysis by evaluating the correlation between centrality in the information exchange network and influence ratings through a dyadic QAP (see Borgatti et al., 2002). The correlation between influence and centrality gave a Pearson's coefficient of $0.762(p<0.000)$. This demonstrates that although influence and centrality in the information exchange network are significantly correlated (as expected), there is still substantial variability between the two. Indeed, if there was no difference at all, Pearson's coefficient would be equal to 1 . The differences between influence and centrality are substantial enough to merit further investigation, since this first result shows that although influence and information centrality are associated, they are not the same thing (H1).

When evaluating the centrality in the information exchange network, we observed that central actors came from all sectors and states. Among the six most central actors in terms of information exchange, two came from civil society, two from the private users category, and two from a government entity. Moreover, the three different states are represented through these actors. This suggests that actors exchange information with others from a variety of backgrounds. It is important to clarify that among civil society representatives in the committee, there were no large NGOs with budgets comparable to those of the private user representatives. Additionally, although one of the two government entity representatives from the six most central actors was a representative of a state-level organization, the other represented a small municipality. These observations together suggest that a variety of reasons, not solely explained by actors' access to financial resources or to formal authority, might explain why actors exchange information with others. In other words, actors positions in social structures (resources, formal authority) preceding 
their interaction with others in the forum do not seem to be the sole guiding factor in the way actors exchange information. Otherwise we would observe that the most central actors are mostly resource-rich actors or actors with access to formal authority. Additionally, our previous study showed that the actors rated as the most highly influential also came from a diversity of backgrounds: Two of them were representatives of private users, two were representatives of civil society, and two others of government entities (Mancilla García \& Bodin, 2018). While some of the most central actors in the information exchange network are among the most influential, not all of them are.

We used SEM to evaluate whether attending different forums produced a significant direct effect in terms of augmenting influence and information degree centrality or whether the effect on information degree centrality was mediated through the level of influence (Fischer \& Sciarini, 2016).

Table 1. Structural equation modeling (SEM1) to explore effect of influence on information (using standardized coefficients).

\begin{tabular}{|l|c|c|}
\hline \multicolumn{2}{|l|}{ Coefficient } & $p$ value \\
\hline Information in-degree $\leftarrow$ & 0.6328536 & 0.000 \\
\hline Normalized influence rating & 0.2072994 & 0.018 \\
\hline Number of forums & 0.2365686 & 0.015 \\
\hline Normalized influence rating $\leftarrow$ & & \\
\hline Number of forums & 0.5017706 & 0.000 \\
\hline
\end{tabular}

Source: Authors' summary of results.

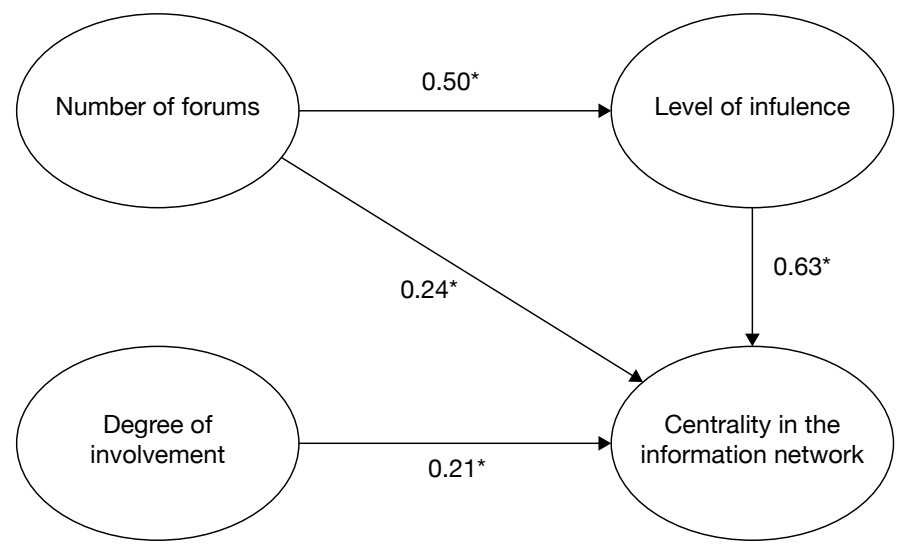

Figure 2. Summary of SEM1.

Source: Authors' summary of results. 
SEM1 shows that the direct effect of the number of forums attended on information exchange network centrality is significant but limited, while it is key in explaining influence (Table 1, Figure 2). This confirms the hypothesis that the number of forums attended has a direct effect on both influence and information degree centrality (H3). It also provides support for the hypothesis that the more influential an actor is, the more central they are in the information exchange network (H2A).

We then reversed the assumed causal directionality between level of influence and information exchange centrality (Table 2, Figure 3), to test whether centrality in the information exchange network explained high influence.

Table 2. Structural equation modeling (SEM2) to explore effect of information on influence (using standardized coefficients).

\begin{tabular}{|l|c|c|}
\hline \multicolumn{2}{|l|}{ Coefficient } & $p$ value \\
\hline Normalized influence rating $\leftarrow$ & 0.7512243 & 0.000 \\
\hline Number of forums & 0.057579 & 0.626 \\
\hline Information in-degree $\leftarrow$ & 0.531643 & 0.000 \\
\hline Number of forums & 0.2732413 & 0.017 \\
\hline Degree of involvement & & \\
\hline
\end{tabular}

Source: Authors' summary of results.

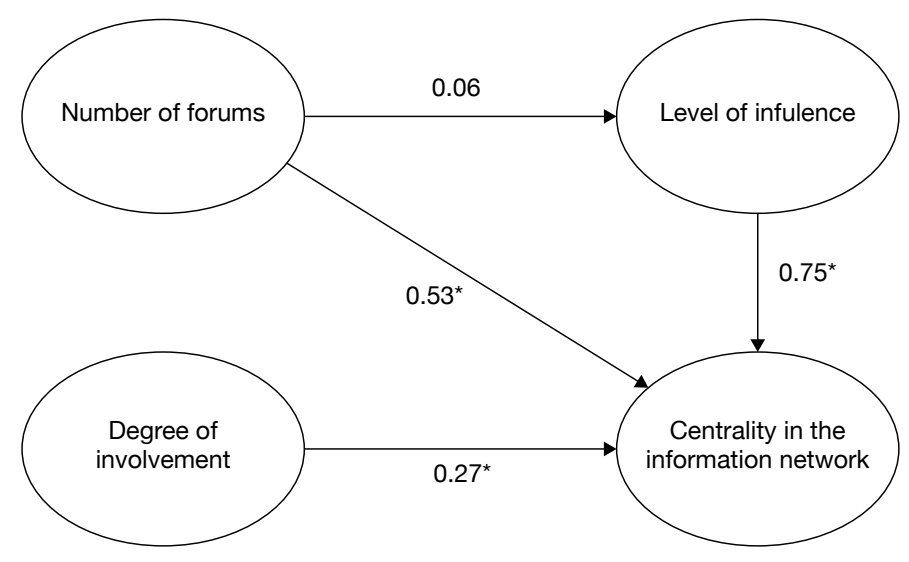

Figure 3. Summary of SEM2.

Source: Authors' summary of results.

In this case, SEM2 shows that the direct effect of the number of forums attended on the influence rating is not significant, while its effect is significant on information centrality. Thus, in this case, the hypothesis that the number of forums attended has a direct effect on both influence and information degree centrality $(\mathrm{H} 3)$ is only partially true (Table 2). We also observe that information has a strong and significant effect in explaining influence $(\mathrm{H} 2 \mathrm{~B})$. 
This second model (SEM2) gave reasonably good fit $(\mathrm{RMSEA}=0.044$; CFI $=0.999)$, however not as good as the first model SEM1 (RMSEA $=0.000$; $\mathrm{CFI}=1.000)$. Hence, in comparing these different models, our results gave stronger support for the following hypotheses: (1) the more influential an actor is, the more central they are in the information exchange network (H2A); and (2) the effect of forum participation on centrality in the information exchange network is to a large extent mediated by its effect on influence (H4A). Our results gave weaker support for the following hypotheses: (1) the more central an actor is in the information exchange network, the more influential they are (H2B); and (2) the effect of forum participation on influence is to a large extent mediated by its effect on information exchange (H4B). Our results also support the hypothesis that forum participation has a direct effect on influence and on information exchange $(\mathrm{H} 3)$.

\section{Discussion}

Our results show that central actors, in terms of information exchange, and actors perceived as highly influential, might emerge from any of the sectors. These results need to be read against the historical background of the region, in which civil society actors, peasant communities, and small municipalities have largely been excluded from management (Abers \& Keck, 2009; Mancilla García \& Bodin, 2018; Mancilla Garcia, Hileman, Bodin, et al., 2019). Among our interviewees, those who had participated in the design and creation of the committees pointed out that the inclusion of actors from civil society was perceived as a key challenge at the time of designing the committees. The fact that we find actors from civil society actively engaged in the network of information exchange and perceived as highly influential shows that including civil society actors in the process of management has been at least partly achieved. Moreover, our interviewees from small NGOs indicated that, notwithstanding the challenges (such as the necessary fluency in technical discourses to be able to meaningfully contribute to discussions: see Mancilla García \& Bodin, 2019, for more details), their participation in the committees allowed them to have a say in the governance of the basin.

Previous literature has argued that government entities in the Global South do not always hold sufficient authority and can be dominated by resource-rich private actors (Abers \& Keck, 2009), which challenges institutionalist perspectives. In our particular case, we observed different degrees of authority among government entities. In particular, municipalities, and even more so small municipalities, did not seem to have access to sufficient resources to comply with their responsibilities, let alone to determine the political agenda (for more details, see Mancilla Garcia, Hileman, Bodin, et al., 2019). This is why it is particularly significant that small 
municipalities are one of the two government entities among the most influential and the most central actors in terms of information exchange, suggesting that, at least to a certain extent, this type of actor can also play an active role in the committee.

The quantitative results, supported by our qualitative data, seem to go against the idea that differences in preexisting structures (such as resources and formal authority) always lead to the same actors being central and influential and that such structures would be impossible to change. Indeed, actors among the most central and the most influential were from a variety of group origins, including civil society, a key group that the designers of the councils sought to include. This resonates with recent studies' findings (Ingold \& Leifeld, 2016; Sciarini et al., 2015), and contributes to challenging the institutionalist hypotheses that formal authority (of the kind certain government representatives hold) is typically the main way to become influential (Dahl, 1994), as well as to challenging the literature on interest groups that argues on the importance of financial resources in becoming influential (Yackee $\&$ Yackee, 2006). This provides support for Giddens's definition of agency, since we do not observe a pure reproduction of structures as one would expect to find from a structuralist perspective. Instead, we find influential actors from a diversity of backgrounds and particularly from those groups that were historically excluded from management.

However, during our interviews some actors were critical of the deliberative system and specifically complained that the committees had unintended negative effects. According to these interviewees, by leading to the development of good relationships between representatives from civil society and from private users, civil society representatives refrained from pushing for a rise in the rates of payment for water use, to maintain their good relationships with the users' representatives and thus engaged in a "consensus game" (Whelan \& Lyons, 2005). Moreover, some of our interviewees pinpointed that in cases of crisis-such as the management of the drought crisis in São Paulo in 2014-the positions of the committee were disregarded and bypassed by traditional power-holders such as the governors of the states. Our interpretation is that although the committee as a whole seem to have come a long way in implementing a participatory system, this should not be taken for granted. Indeed, there are exterior structures that still matter for the management of the system and that might become dominant at certain times.

It is also important to note that CEIVAP is free to use the resources collected from private users in the basin-through the payment for water use scheme implemented in the basin (Abers \& Keck, 2006; Ioris, 2009)—as the plenary considers appropriate. This means that if actors manage to advance their agendas in the forum, this will have an impact on the management system. For example, our interviews suggest that the work within the committee-making proposals and substantiating them with diagnoses on the system state-of previously excluded actors such as environmentalists has had an effect on the kind of projects approved. CEIVAP has 
successfully developed a set of projects since it was created in 1997, among which 13 programs of environmental education. Between 2013 and 2016, nearly 55 percent of the money spent-USD22 million-was spent in projects of environmental quality recovery, which involved setting sanitation programs as a priority. Almost USD4 million $\longrightarrow 9$ percent of the total amount spent-was spent on protection and use of water resources. Projects in this component include a project on payment for ecosystem services, recovery and protection of permanent preservation areas, and the creation of a database from which maps can be built (AGEVAP $\left.{ }^{4}, 2016\right)$. The creation of maps is part of the tasks related to the diffusion of information, which has also involved the holding of courses and workshops in diverse areas of the basin.

Our results suggest that in order to become influential or central in the information exchange network, actors should try and invest in attending multiple forums. These findings directly speak to the idea put forward by Giddens, and Long and Long, that structures-in this case the formal institutional network of governance-should actively be used by actors to achieve their goals (Giddens, 1984; Long \& Long, 1992). Our results show that the opportunity for actors to increase their influence by participating in multiple formal forums is not restricted to traditionally powerful actors with access to resources, and responds to deliberate action by all actors. Thus, this suggests that the committees provide a platform wherein actors can do something to improve their influence, such as attending other forums.

These results also provide lessons for scholars adopting a perspective inspired on political ecology or those working on leadership studies. Indeed, while those perspectives can help to guide the questions asked on power dynamics and on the role of particular actors, respectively, our results show that they would gain from incorporating insights from structuration theory. Network analysis provides a concrete way to investigate both the effects of structure and agency that can be useful for these perspectives.

It is important to specify that being very involved in one forum, considering it fundamental for one's work, is not the same as participating in many forums. If actors want to increase their influence, they should invest their limited time and resources in participating across multiple forums, not only one forum. It is furthermore interesting to note that the variable "degree of involvement" serves to explain information centrality, which means that actors who invest themselves in the committee work become more central in the information exchange network. Increased involvement might improve an actor's reputation as knowledgeable and thus increase their centrality in the information exchange network, but not necessarily their influence (see also Mancilla García \& Bodin, 2018). By participating heavily in the committee, actors seem to be building networks, but not necessarily influence.

4 Associação Pró-Gestão das Águas da Bacia Hidrográfica do Rio Paraíba do Sul (Association for the Management of the Waters of the Paraíba Do Sul River Basin). 
While the analysis above indicates that influence ratings and information degree centrality seem to respond to similar dynamics, our analysis also showed that both measures are separate. Although actors might behave in ways that increase both their influence ranking and their information exchange network centrality, some strategies might benefit only one of those two. For example, we observed that certain actors were very present in online media such as WhatsApp groups on water governance, which they used to communicate all sorts of information on the state of the rivers. While these actors were well known to others, they were not necessarily perceived as influential. Indeed, the information they communicated might serve to feed the management system (such as information on water levels, ecosystem health measures, etc.) but not necessarily determine the agenda. In our qualitative data, we also find cases of actors who were quite central in the information exchange network but who were considered by others as having little influence. For example, one actor-representative of the users-had participated in the committee for several years and had been brought to the committee through a personal connection to a member. The actor enjoyed participating in the committees because they learned about water governance and particularly about basin-perspectives. The sustained participation over time, as well as their willingness to engage with diverse issues, had made them well known among committee participants. However, they rarely expressed strong opinions on the issues discussed or defended any particular position strongly enough to be considered influential.

Conversely, we find examples of actors who were influential but not central in the information exchange network. For example, an actor might be considered influential because they hold a particularly powerful formal position within the committee, but that does not mean that they will be actively engaged in networks of information exchange. According to our interviewees, this tends to happen with actors occupying a high-ranking administrative position in the committee. These actors are considered highly influential during the time of their mandate; however, they frequently are very busy and tend, for example, not to stay until the end of plenary meetings and not to attend other events (such as environmental education activities, etc.), which means that they are rarely available for others. Therefore, our qualitative data provide cases in which influence and information exchange centrality are clearly separate, and as we saw from the quantitative analysis.

\section{Limitations}

The main limitation of our study is the lack of longitudinal quantitative data. Without such data, assessing causal directionally empirically is inherently difficult. The SEM results gave more support for the model that reflected the hypotheses that (1) the more influential an actor is, the more central they are in the information exchange network (H2A), and (2) the effect of forum participation on centrality in the information exchange network is to a large extent mediated by its effect on influence (H4A). However, we cannot rule out the hypotheses that (1) the more 
central an actor is in the information exchange network, the more influential they are (H2B), and (2) the effect of forum participation on influence is to a large extent mediated by its effect on information exchange (H4B). We also cannot rule out the hypothesis that forum participation has a direct effect on influence and on information exchange (H3), which is only partially excluded.

Importantly, our qualitative data corroborated the ways we interpreted our quantitative results. Hence, in sum, although we acknowledge the limitation deriving from lack of longitudinal data, we maintain that our results provide empirical support favoring certain causal pathways over others. However, we wish to emphasize that although our focus has been on disentangling causal directions, we nonetheless acknowledge that directionality likely goes in both ways (i.e., feeds back), although we maintain that our results demonstrate that certain directions are stronger than others.

Additionally, the study did not consider the effect of participating in one or several of CEIVAP's sub-forums (such as the technical chamber, the directorate, or working groups) on influence or information degree centrality. We did not consider these data to be reliable since the effect of someone participating in one of these subgroups, and it being known and acknowledged by participants in the plenary, seemed to suffer from time lapses. Indeed, in the interviews, participants remembered others being part of the technical chamber in previous years, but did not necessarily know who was part of it at the time of the interview. Moreover, in the specific case of the technical chamber and working groups, organizations represented in the plenary did not necessarily send their plenary representative to the technical chamber; they could send someone else from the organization. This meant that actors who had newly joined the plenary did not know these other actors. For these reasons, we preferred to exclude this attribute.

Finally, in this study we focused on information exchange. Networks made up of other types of social relationships could have led to different results. However, we argue that information exchange is a broadly spanning type of relationship, which often comes together with other types of relationships (e.g., trust). Hence, we in part consider it being a proxy for other kinds of relationships the actors associate with a positive social relationship.

\section{Conclusion}

In this paper we have explored the ways in which centrality in the information exchange network and influence are causally connected and how they can be explained by analyzing actors' actions and the structures in which they are embedded. We have seen that high influence and centrality in the information exchange network are related. Attending multiple forums seems to explain influence and information 
degree centrality. Moreover, we have seen that influence has a strong impact in determining information degree centrality, although we also found support for the reverse directionality, albeit with a lower model fit.

We have also seen, through the use of our qualitative data, that there are activities and structures that have an impact on information degree centrality but not on influence, and vice versa. On the one hand, being deeply involved in CEIVAP's work is beneficial in terms of information degree centrality, but not necessarily in terms of achieving high influence. On the other hand, occupying a position of high responsibility in the committee-for example, being the president of the directorate-leads to being perceived as highly influential, but this has no allencompassing impact on an actor's centrality in the social network. These different elements seem to suggest that actors have opportunities to use the available formal institutional structures to act in ways that benefit them. For example, an actor can choose to participate in many forums - which is made possible by the formal creation of such participatory forums in the Brazilian system of water governanceand thus exert their agency to become influential by putting existing structures to good use.

Future research should investigate with longitudinal studies how different eventssuch as political changes or water availability crisis-impact the perception of influence and the capacity of actors participating in the committees to effectively use their power to steer the system. Additionally, future studies should try to further explore how actors strategically use different structures at their disposal to advance their positions in different networks and forums than the ones studied here-such as project collaboration, alignment of voting behavior, or strategies of participation across forums - and how that relates to their perceived influence.

\section{References}

Abers, R., \& Keck, M. (2006). Muddy waters: The political construction of deliberative river basin governance in Brazil. International Journal of Urban and Regional Research, 30(3), 601-622. doi.org/10.1111/j.1468-2427.2006.00691.x

Abers, R., \& Keck, M. (2009). Mobilizing the state: The erratic partner in Brazil's participatory water policy. Politics \& Society, 37(2), 289-314. doi.org/10.1177/0032329209334003

AGEVAP. (2016). Relatório anual 2016 e consolidação de dados de 2013 a 2016 para acompanhamento das açóes executadas com recursos da cobrança pelo uso da água (Annual report 2016 and consolidated data 2013-2016 on use of funds raised from water extraction charges). Associação Pró-Gestão das Águas da Bacia Hidrográfica do Rio Paraíba do Sul (Association for the Management of the Waters of the Paraíba Do Sul River Basin). ceivap.org.br/downloads/relatorio-anual-de-acompanhamento-pap-2016.pdf 
Ardoin, N. M., Gould, R. K., Kelsey, E., \& Fielding-Singh, P. (2014). Collaborative and transformational leadership in the environmental realm. Journal of Environmental Policy \& Planning, 17(3), 360-380. doi.org/10.1080/1523908X.2014.954075

Bakker, K. (2013). Constructing "public" water: The World Bank, urban water supply, and the biopolitics of development. Environment and Planning D: Society and Space, 31(2), 280-300. doi.org/10.1068/d5111

Bebbington, A. (1999). Capitals and capabilities: A framework for analyzing peasant viability, rural livelihoods and poverty. World Development, 27(12), 2021-2044. doi.org/ $10.1016 / S 0305-750 X(99) 00104-7$

Berardo, R. (2013). The coevolution of perceptions of procedural fairness and link formation in self-organizing policy networks. Journal of Politics, 75(3), 686-700. doi.org/10.1017/ S0022381613000455

Borgatti, S. P., Everett, M. G., \& Freeman, L. C. (2002). UCINET for Windows (Version 6.642) [Computer software]. Analytic Technologies. sites.google.com/site/ucinetsoftware/home

Budds, J., \& Hinojosa, L. (2012). Restructuring and rescaling water governance in mining contexts: The co-production of waterscapes in Peru. Water Alternatives, 5(1), 119-137. www.water-alternatives.org/index.php/volume5/v5issue1/161-a5-1-8/file

Burt, R. S. (2003). The social capital of structural holes. In M. F. Guillen, R. Collins, P. England, \& A. Meyer (Eds.), The new economic sociology: Developments in an emerging field. Russell Sage Foundation.

Dahl, R. (1994). A democratic dilemma: System effectiveness vs. citizen participation. Political Science Quarterly, 109(1), 23-34. jstor.org/discover/10.2307/2151659?uid= $3738016 \&$ uid $=2129 \&$ uid $=2 \& u i d=70 \&$ uid $=4 \&$ sid $=21102194842101$

Dür, A., \& de Bièvre, D. (2007). Inclusion without influence? NGOs in European trade policy. Journal of Public Policy, 27(1), 79-101. doi.org/10.1017/S0143814X0700061X

Few, R., Brown, K., \& Tompkins, E. L. (2007). Public participation and climate change adaptation: Avoiding the illusion of inclusion. Climate Policy, 7(1), 46-59. doi.org/ $10.1080 / 14693062.2007 .9685637$

Fischer, M., \& Sciarini, P. (2016). Drivers of collaboration in political decision making: A cross-sector perspective. The Journal of Politics, 78(1), 63-74. doi.org/10.1086/683061

Gebara, M. F., Fatorelli, L., May, P., \& Zhang, S. (2014). REDD+ policy networks in Brazil: Constraints and opportunities for successful policy making. Ecology and Society, 19(3). doi.org/10.5751/ES-06744-190353

Giddens, A. (1984). The constitution of society: Outline of the theory of structuration. Polity Press.

Hileman, J., \& Bodin, Ö. (2018). Balancing costs and benefits of collaboration in an ecology of games. Policy Studies Journal, 47(1), 138-158. doi.org/10.1111/psj.12292 
Ingold, K., \& Leifeld, P. (2016). Structural and institutional determinants of influence reputation: A comparison of collaborative and adversarial policy networks in decision making and implementation. Journal of Public Administration Research and Theory, 26(1), 1-18. doi.org/10.1093/jopart/muu043

Ioris, A. A. R. (2009). Water reforms in Brazil: Opportunities and constraints. Journal of Environmental Planning and Management, 52(6), 813-832. doi.org/10.1080/096405 60903083756

Kaplan, D. (2009). Structural equation modeling: Foundations and extensions (2nd ed.). SAGE Publications. doi.org/10.4135/9781452226576

Krackhardt, D. (1988). Predicting with networks: Nonparametric multiple regression analysis of dyadic data. Social Networks, 10(4), 359-381. doi.org/10.1016/0378-8733 (88)90004-4

Lister, R. (2004). Poverty. Polity Press.

Long, N., \& Long, A. (1992). Battlefields of knowledge: The interlocking of theory and practice in social research and development. Routledge.

Lubell, M., Henry, A. D., \& McCoy, M. (2010). Collaborative institutions in an ecology of games. American Journal of Political Science, 54(2), 287-300. doi.org/10.1111/j.15405907.2010.00431.x

Mancilla García, M. (2015). Does social media benefit dominant or alternative water discourses? Water Alternatives, 8(2), 125-146. www.water-alternatives.org/index.php/ alldoc/articles/vol8/v8issue2/284-a8-2-7

Mancilla García, M., \& Bodin, Ö. (2018). Participation in multiple decision making water governance forums in Brazil enhances actors' perceived level of influence. Policy Studies Journal, 47(1), 27-51. doi.org/10.1111/psj.12297

Mancilla García, M., \& Bodin, Ö. (2019). Participatory water basin councils in Peru and Brazil: Expert discourses as means and barriers to inclusion. Global Environmental Change, 55(2019), 139-148. doi.org/10.1016/j.gloenvcha.2019.02.005

Mancilla García, M., Hileman, J., \& Bodin, Ö. (2019). Collaboration and conflict in complex water governance systems across a development gradient: Addressing common challenges and solutions. Ecology and Society, 24(3), Article 8. doi.org/10.5751/es-11133-240328

Mancilla García, M., Hileman, J., Bodin, Ö., Nilsson, A., \& Jacobi, P. R. (2019). The unique role of municipalities in integrated watershed governance arrangements: A new research frontier. Ecology \& Society, 24(1). doi.org/10.5751/ES-10793-240128

Morse, W. C., McLaughlin, W. J., Wulfhorst, J. D., \& Harvey, C. (2013). Social ecological complex adaptive systems: A framework for research on payments for ecosystem services. Urban Ecosystems, 16(1), 53-77. doi.org/10.1007/s11252-011-0178-3

Ostrom, E. (2005). Understanding Institutional Diversity. Princeton University Press. 
Sciarini, P., Fischer, M., \& Traber, D. (2015). Political decision-making in Switzerland: The consensus model under pressure. Palgrave Macmillan. doi.org/10.1057/9781137508607

Stones, R. (2005). Structuration theory. Palgrave Macmillan. doi.org/10.1007/978-0-23021364-7

Whelan, J., \& Lyons, K. (2005). Community engagement or community action: Choosing not to play the game. Environmental Politics, 14(5), 596-610. doi.org/10.1080/096440 10500257888

Yackee, J. W., \& Yackee, S. W. (2006). A bias towards business? Assessing interest group influence on the U.S. bureaucracy. The Journal of Politics, 68(1), 128-139. doi.org/ 10.1111/J.1468-2508.2006.00375.X 
This text is taken from Human Ecology Review, Volume 26, Number 2, 2020, published by ANU Press, The Australian National University, Canberra, Australia. doi.org/10.22459/HER.26.02.2020.02 